\title{
A Comparison of Users Data in Retention and Disposition Processes in an Internet Website: The Ministry of Foreign Affairs of Israel as a Case Study*
}

\author{
Silvia Schenkolewski-Kroll \\ Bar Ilan University \\ Ramat Gan, Israel \\ sil_sch@netvision.net.il \\ Assaf Tractinsky \\ Israel State Archives \\ 14 Hartom St., Har Hotzvim, Jerusalem, Israel \\ assaft@archives.gov.il
}

\section{Summary}

In our appraisal of the English website of Israel's Ministry of Foreign Affairs, we took into account the manner in which Israeli government ministries conduct their records management. However, due to the unique characteristics of internet websites, special parameters are needed, such as harvesting and user behavior. We conducted a functional analysis of user behavior on the MASHAV subsite and the "Foreign Policy" division of the ministry's website, using the "About Israel" division as a control unit for comparison. Since MASHAV provides information and services to users, it is possible to use the retention periods set in the Archives Law 5715-1955 for some of its parts. "Foreign Policy" is an informative division whose documents are replaced according to changing event.

In all three, we examined and analyzed the number of users and the length of time spent on the site during each access. The comparison was done for February and October 2014, and for the total year. The results show that in the "Foreign Policy" and "About Israel" divisions the number of users was greater than in MASHAV and fluctuated depending on the circumstances and events, while users remained in the MASHAV subsite for longer periods of time.

Keywords: appraisal; users; Ministry of Foreign Affairs - Israel

\footnotetext{
* This article is part of a research study of InterPARES Trust "Research of retention and disposition processes in an internet website of the Government of Israel: The Ministry of Foreign Affairs as case study" (Unpublished).
} 


\section{Archival Appraisal Processes in the Ministry of Foreign Affairs of Israel}

As a short introduction, it should be noted that the Ministry of Foreign Affairs, as an integral part of the governmental system of the State of Israel, conducts its records management in accordance with the Archives Law 5715-1955. The State Archivist, through the Israel State Archives (ISA) and its administration, is responsible for enforcing the Law in all government ministries, state institutions, and local government. As such, archival appraisal, which is part of the Ministry of Foreign Affairs' records management, is executed in accordance with the system set forth by the ISA. ${ }^{1}$

A special department within the Ministry of Foreign Affairs, the Records Management and Databases Center, is responsible for records management. It has a long tradition of proper records management ensuring that all records of all the Ministry's units, including those in Israeli missions worldwide, undergo archival appraisal, including determination of retention schedules. ${ }^{2}$ This pertains to both traditional and electronic records, so they do not differ in terms of appraisal criteria. Beginning in 2000, the Ministry integrated the retention schedules of electronic records. To date, no material from the Ministry's electronic systems has been disposed of. Retention schedules will serve the Ministry of Foreign Affairs for two purposes in the future: the first, to classify material in the electronic systems according to level of importance; and the second, to transfer material intended for permanent retention to the ISA. Regarding preservation of record authenticity, we will need to re-examine this issue within the framework of the abovementioned processes ${ }^{3}$.

The Ministry of Foreign Affairs' websites, including the website serving as a case study, have yet to be addressed within the framework of the archival appraisal process. ${ }^{4}$

\footnotetext{
${ }^{1}$ Shoham, S and Schenkolewski-Kroll, S (2010) Israel: Libraries, Archives and Museums,' Encyclopedia of Library and Information Sciences, Third Edition, 1: 1, 3035 - 3040

${ }^{2}$ Prime Minister Office, State Archivist, Higher Archives Council, Protocols and Reports, Jerusalem, from years: 1972, 1982, 1985, 1986, 1987, 1988, 1991 (Hebrew), and Arie Zini, The Place of the Filing Unites in the Computerization Era, 2011(Hebrew) http://www.archives.gov.il/ ArchiveGov/meyda/ElectronicRashuma/YomIyun2010.htm

${ }^{3}$ Schenkolewski-Kroll, S. and Tractinsky, A, (2015). "Archival Appraisal Processes in the Ministry of Foreign Affairs of Israel" in Ministry of Foreign Affairs website final Report, Submitted to the European team of InterPARES Trust (Unpublished)

${ }^{4}$ http://mfa.gov.il/MFA/Pages/default.aspx
} 


\section{Attempts to Find a Basis for Appraisal in Existing Retention Schedules}

After examining the various sections we decided, at this stage, to deal with an appraisal of the new website, beginning with 2013, with a view to the future, rather than to conduct a retrospective appraisal. This decision was taken due to the different characteristics of the website that was created in 1993 and the difficulties that might arise in an attempt to analyze the two systems concurrently. Two additional topics may affect website appraisal: first, harvesting and its application to the website or to portions of the site ${ }^{5}$; and secondly, the users - an issue which to the best of our knowledge has not been taken into consideration in any website appraisal framework. Can the ways in which the website is used - by user segmentation, by website sections and the way they are divided internally - be a factor sufficiently significant to serve as an appraisal and retention schedule criterion? Is it possible that a large number of views of a website section or of a certain website page points to their importance in the eyes of the users? In addition, in light of the research findings, the Ministry of Foreign Affairs will have to conduct its website records according to records management procedures, in order to create and appraise authentic records.

This article focuses mainly on analysis of the statistical measurements of user behavior. The harvest method mentioned below serves only for background in presenting the main subject.

\section{Appraisal of Archival Material - Websites}

Archivists faced a new challenge with the emergence of websites in the 1990s: how to cope with electronic records that were organized in their entirety in a manner they had not done previously. The purpose of an organizational website is to make information accessible to the general public about the organization or institute, its objectives, activities, the content of its material, and any other information which it deems necessary, worthwhile, or suitable to be made public. The material posted on the site can be divided into two main groups: records intended to distribute information as a goal within itself; and records that constitute an alternative to administrative services, such as posting forms that are part of a service to the public and receiving them back on-line, in order to implement the public's rights. Due to the nature of the service and its operation, a website is defined as social media. The records constituting the site have different diplomatic forms: some conform to traditional and electronic records, which are the result of a service, and others are more similar to publications - these are

\footnotetext{
5 Brown A. (2006), Archiving Websites: A Practical Guide for Information Management Professionals. Facet Publishing. pp. 24-41; TNA (2011), Web Archiving Guidance (2011). $\mathrm{http}$ //nationalarchives.gov.uk/documents/information-management/web-archiving-guidance.pdf; TNA (2014), Operational Selection Policy OPS 27, UK Central Government Web Estate, http://www.nationalarchives.gov.uk/documents/information-management/osp27.pdf
} 
part of what was defined above as information. Everything depends on the nature of the site and its purposes. In light of the above, one of the special characteristics of a website is the constant updating of the records appearing on it, with the goal of providing current information in all the fields with which the site is concerned. Updates may be made as often as several times a day during critical periods, and up to every few weeks or more when dealing with permanent administrative material. ${ }^{6}$ Because one of the objectives of the site is the distribution of current information, the number of users is one of the characteristic criteria that determine at any one time the measure of the site's success, as opposed to other records which are not made available to the public until they become archival material. This situation raises questions as to the nature of the appraisal and retention of records whose source is the Internet: is it possible to use the same rules of a particular appraisal method, which are applied to traditional and electronic records that deal with the same subjects in the administration of the same organization that operates the website, or is there a need to find appraisal methods that meet the specific needs of a website? Can the number of the users of the site's various sections serve as a criteria for determining the importance of a site, or one of its parts, and influence the determination of a retention schedule for specific materials?

With regard to the process of choosing records for retention on websites or on some of their pages, the system for doing so is harvesting. This refers to a type of software that makes it possible to locate the site or its sections; "to harvest" is to create copies in the computer on a specific date and at intervals of time that have been determined by those responsible for this process. This makes it possible to adapt harvested material to the structure of the site, its content, the time, and a specific situation. For example, on the Ministry of Foreign Affairs site, during times of war material will be harvested at very short periods of time, compared with harvesting information during periods of calm. Retention by harvest parameters is accepted practice, and is mentioned in the literature. ${ }^{7}$ The issue of the number of users and its influence on appraisal has not yet been dealt with in the literature. Only a systematic study over a specific period of time of the number of users compared with the material presented on various parts of the site can provide an answer about this criterion (see below).

For the purpose of demonstration, in this case study of the Ministry of Foreign Affairs site, two of its sections were considered. Two different types were deliberately chosen, each having its own unique characteristics which serve different purposes.

\footnotetext{
${ }^{6}$ Brown A. (2006), Archiving Websites: A Practical Guide for Information Management Professionals. Facet Publishing. pp. 24-41

${ }^{7}$ See above note 4 .
} 
One was MASHAV that can be defined as a subsite, since it is operated by an administrative unit having a certain amount of autonomy when compared to other administrative units of the Ministry of Foreign Affairs. It is mainly operational, and serves as a means of fulfilling the functions of the unit responsible for it, such as presenting courses and everything related to them, MASHAV's activities on four continents, and more. The purpose of this subsite is partly informative and partly fulfillment of administrative functions, such as enabling registration for courses. The function of "Foreign Policy," as its name indicates is to present the past and current policy and activities of the Ministry through information from the past and current news. The format of the material is similar to traditional publications in the written and electronic media. ${ }^{8}$

\section{MASHAV}

MASHAV was founded in 1957 with the main purpose of circulating Israel's technological expertise among the developing countries. Today MASHAV is a unit at the Ministry of Foreign Affairs headquarters which works through the Ihud company to service Israeli organizations that deal with international training and consultation for developing countries, providing them with humanitarian as well as technical aid. It implements its training programs with the help of three training centers in Israel. Its fields of activity are those in which Israel has a comparative lead and expertise that have accumulated throughout the years. The subsite includes the structure and activities of the administrative unit. The documents are generally divided into two types: governance and management information, and research and innovative information. The division in which new documents are requested at the greatest frequency is the Newsletter, ranging from one to three documents a month. The site is managed independently by one of the MASHAV staff. ${ }^{9}$

As can be seen in Figure 1, the subsite is divided into seven divisions, some of which are divided into subdivisions.

With regard to divisions, we collected data that would help us with the appraisal according to the categories common to all records: the name of the division, number of documents, document type, date of creation or event, additional documents, internal or external links, and retention schedules. In addition, we examined whether there are links within the division to other places on the site, or off it.

This datum is important to know in order to plan the harvesting process of division and its various parts, or of the entire site. We marked the links with a + when they appeared, and a - when they didn't, as in the "Publications" division. Finally, we noted whether there are retention periods in the Archives Law for

\footnotetext{
${ }^{8}$ See above note 3 .

${ }^{9}$ An Interviews with Avnit Rifkin, the MASHAV webmaster, 2/1/2014
} 
material found in the division. We also noted the retention period and the clause in the Archives Law, as in the division "MASHAV Professional Courses," where the retention period is 10 years after file closure or end of issue. ${ }^{10}$

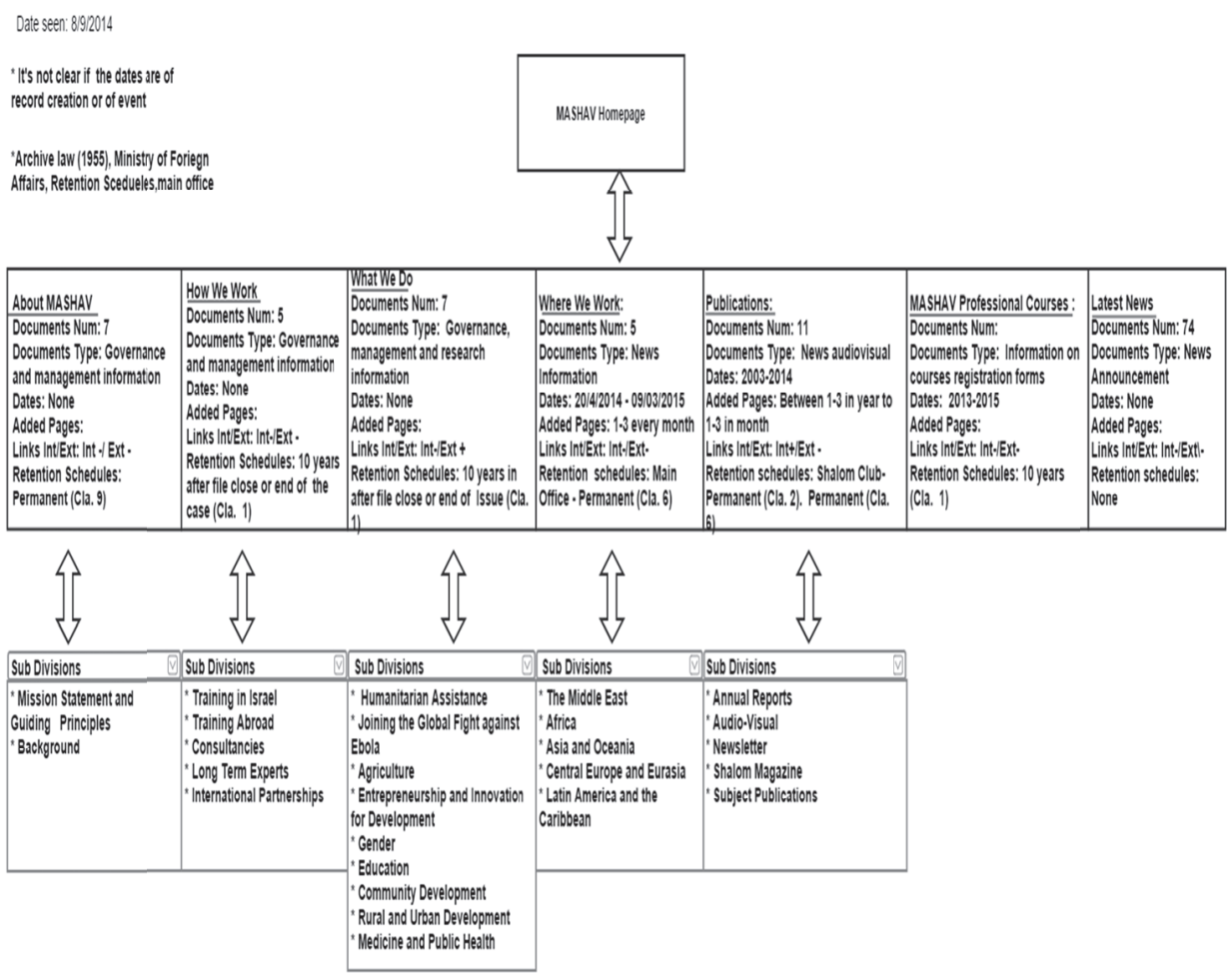

Figure 1 - MASHAV subsite and its seven divisions

\section{Foreign Policy}

The "Foreign Policy" division contains documents describing the foreign relations of the State of Israel. It changes and adds information according to the pace of events; in that, it is similar to traditional and electronic media. Various documents may appear on the site several times - in the divisions of the main page of the "Foreign Policy" division and in other divisions on the site, such as "International Organizations." The fact that the same documents appear in different places on the Ministry's site makes it difficult to determine time periods of updating. Obviously, when diplomatic activities are intensified, such as during Operation Protective Edge, material is updated more frequently, 2-3 times as often, depending on the judgment of the site manager. The main page of the ${ }^{10}$ Archives Law 5715-1955. Regulations and Instructions]p. 20 (Hebrew), http://www.archives.
gov.il/ArchiveGov/meyda/TkufotBiur/taknot.htm 
division then accumulates the latest major newsworthy items on Israel's foreign policy. In cases of such campaigns retention is permanent, especially if one takes into account the fact that the person responsible for the site has already applied a selection process as to which items to post (there are no clear rules on the issue, only personal judgment). ${ }^{11}$

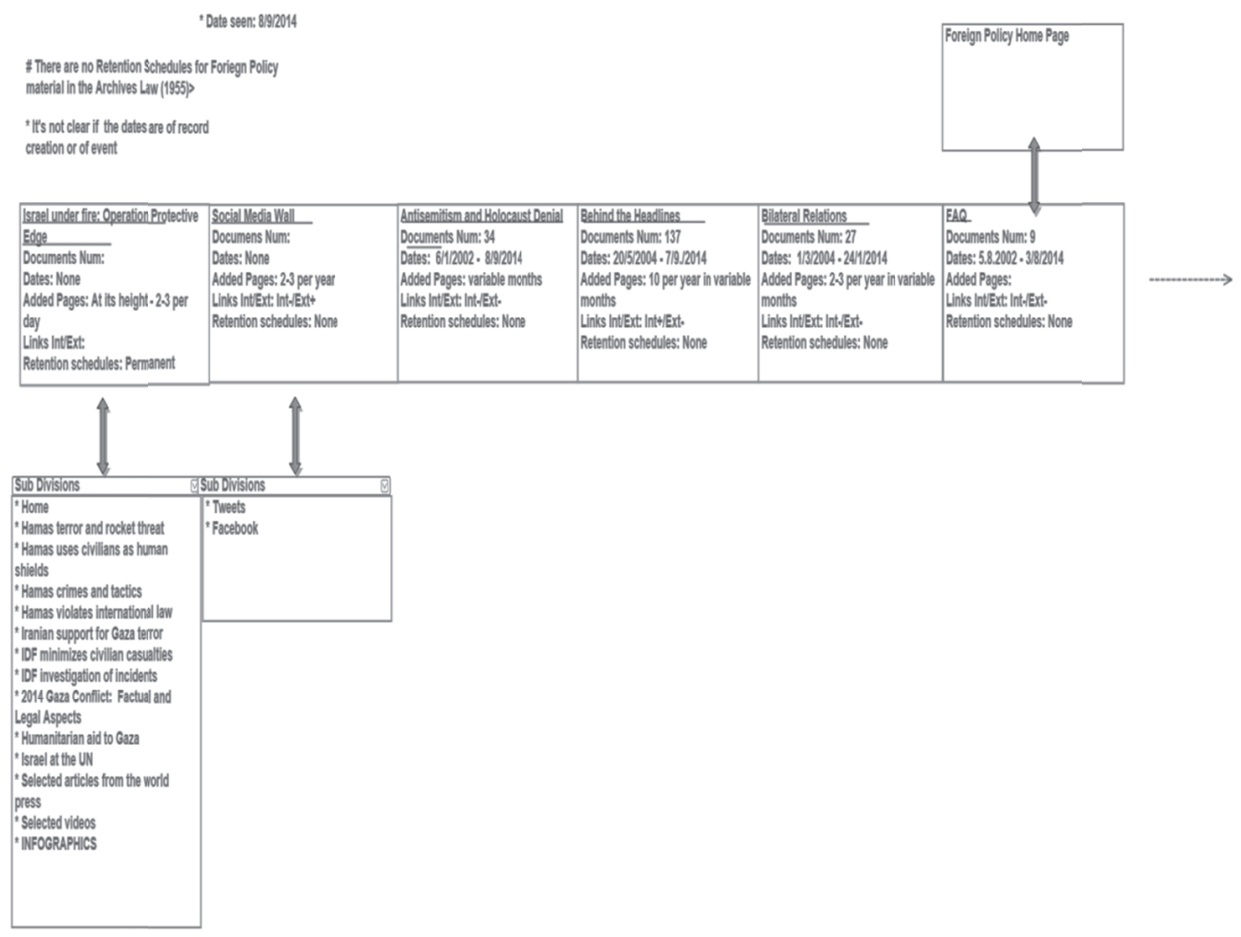

Figure 2A - Foreign Policy section and its twelve divisions

With regard to the divisions, we collected data according to the categories common to all: the name, number of documents, date of creation or event, additional documents, internal or external links, and retention schedules. The category "Document Type," which appears in the MASHAV data, was eliminated in this section because it was difficult to characterize the type of documents it presents. In addition, we examined whether there were links in the division to other places on the Ministry site or outside it. This item is important in order to know how to plan the harvesting process of the division and its various subdivisions or of the entire site. We marked + where links were found, and - where they were not, as was done in the "FAQ" division. Finally, we left in the category of retention periods, despite the fact that we did not find in the Archives

${ }^{11}$ An Interview with Sarah Lederhendler, the MFA webmaster, in 24/12/2013 
Law periods for the material appearing in the section, and marked it "None." Only in "Israel under Fire: Operation Protective Edge" did we note the retention period, since this was a unique event.

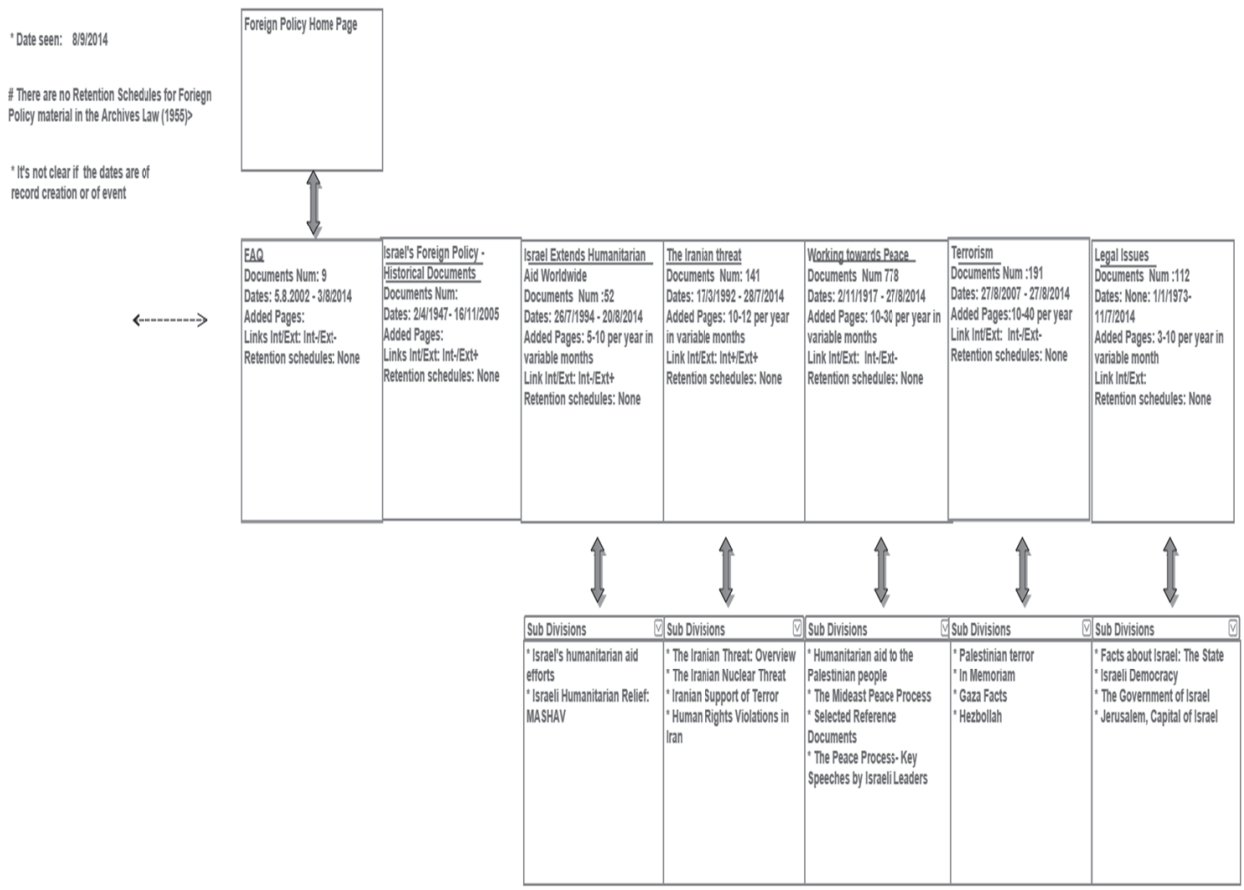

Figure 2B - Foreign Policy section and its twelve divisions - continue

\section{Attempts to Determine Retention Periods for the Two Sections Examined}

Because the Ministry of Foreign Affairs has updated retention periods for the entire administrative structure of the office, ${ }^{12}$ an attempt was made to adapt the retention periods of the records for the two sections studied to the retention periods of corresponding administrative units in the structure of the Ministry. With regard to MASHAV, the parallels exist because that section represents a defined administrative unit. Therefore, clauses 1, 2, 5, 6 and 9 of the Archives Law guidelines, as applied to MASHAV, ${ }^{13}$ compare with the divisions of the MASHAV section (see Fig. 1). The question remains whether this obligates MASHAV to apply its own retention period to its site.

\footnotetext{
${ }^{12}$ Archives Law,5715-1955, Regulations and Instructions, (Hebrew) http://www.archives.gov.il/ ArchiveGov/meyda/TkufotBiur/taknot.htm

${ }^{13}$ See above note 11 .
} 
As for the "Foreign Policy" section, because of its publicist nature it has no parallel in the retention periods that were determined for the Ministry framework; therefore, it seems that only harvesting periods in accordance with the pace of events and/or the number of users can serve as criteria in this case. Since an advance selection of the material presented in this section is made by the person responsible for the site, and despite the fact that the criteria for his/her choices are unclear, the possibility of setting rules for selection has been discounted at this stage of the appraisal. ${ }^{14}$ Therefore, it appears that there is no point in recommending setting retention periods for the "Foreign Policy" section.

From the above two examples, it may perhaps be possible to determine rules with regard to other sections on the site. Each one of them will require a process of study and analysis, both from the aspect of its internal organization and that of its content and the diplomatic form of the records.

\section{A Comparison of User Data}

The purpose of the experimental analysis is to try to integrate users' behavior on the website into the process of its appraisal. The goal of the data presented here is to present trends and estimates in the field, rather than results. The reasons for that are that the material on the website is mostly different than that of the internal organizational systems and, in contrast to those systems, the material on the site is accessible to the public at all times. Therefore, an external element may be required to assist in the site's appraisal, in addition to - or instead of - the criteria usually used in a standard appraisal, such as administrative use or legal, sociological, and research value.

The program we used was "Piwik," 15 an open source system which can be downloaded from the Internet. It was installed on the Ministry of Foreign Affairs' website, in the government servers' farm, instead of the "Share Point" system, which is used on the site and provides similar options.

\section{Organization of the Data}

The Piwik program data were collected from two sections, MASHAV and Foreign Policy, on which we conducted an in-depth study. In addition, a third section - About Israel - was chosen randomly to serve as a control group. The data on the three sections were recorded for the months of February and October 2014, as well as summary data for all of 2014. Comparative reports were produced for the three sections, which present the same data: the number of page views and average time on page during each of the periods studied, with page

\footnotetext{
${ }^{14}$ An Interview with Sarah Lederhendler, the MFA webmaster, in 24/12/2013.

${ }^{15} \mathrm{http} / /$ piwik.org/

${ }^{16}$ See for example: View Web Analytics Reports (SharePoint Server 2010). https://technet. microsoft.com/en-us/library/ee663487(v=office.14).aspx
} 
views representing the number of times a page was visited. The average time on page represents the average amount of time visitors spent on a page.

February 2014

A. Number of Page Views in the Sections

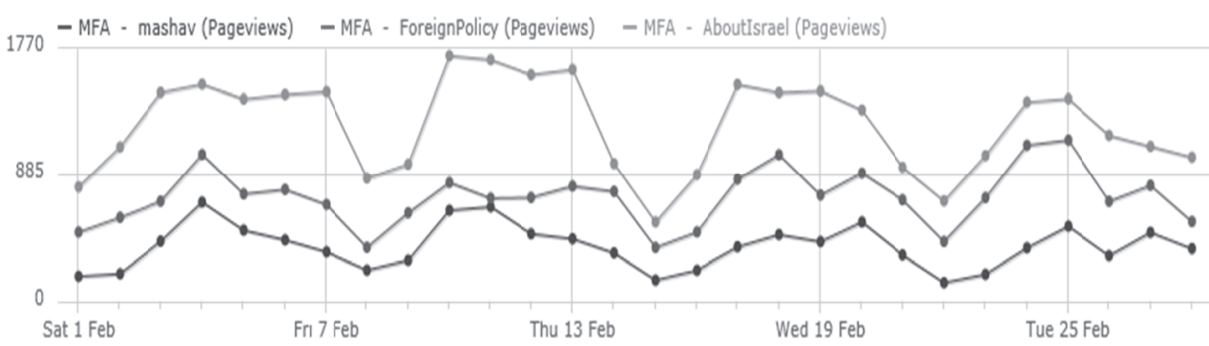

Figure 3 - The graph shows the number of views in the various pages of the three sections: MASHAV, Foreign Policy, and About Israel. (February 2014)

1. It can be seen that there are page views throughout the entire month in all the sections.

2. About Israel is the section most viewed, and the least viewed is that of MASHAV.

B. Time Spent on a Page

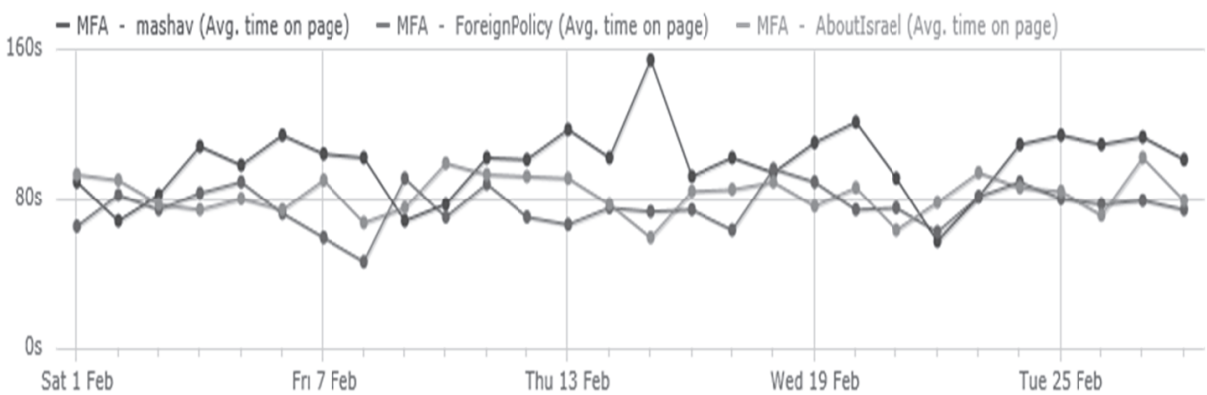

Figure 4 - The graph shows the average amount of time spent by users on the various pages in the three sections: MASHAV, Foreign Policy, and About Israel. The data are summarized in the system up to the section level (February 2014).

1. The average amounts of time spent in the three sections range around 80 seconds.

2. Most of the longest periods of time are found in MASHAV, with the peak of time spent on a page occurring on February 15, in that section, at a little less than 160 seconds. 
October 2014

A. Number of Page Views in the Sections

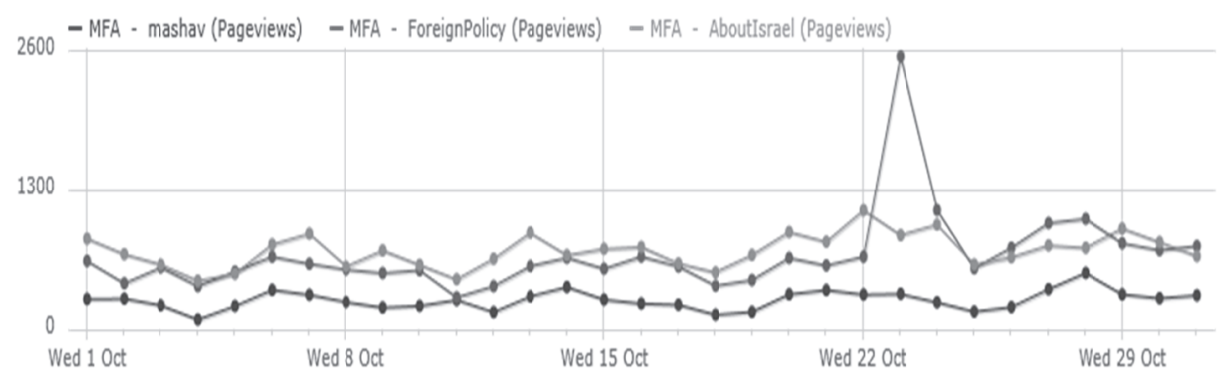

Figure 5 - The graph shows the number of views in the various pages of the three sections: MASHAV, Foreign Policy, and About Israel (October 2014).

1. All the sections were viewed during the month.

2. The number of page views - in general, the most page views occurred in "About Israel" and following that, "Foreign Policy." The fewest page views were in MASHAV.

A special peak can be seen on 23 October in "Foreign Policy." This may be related to a special incident which took place the previous day in Jerusalem: an Arab terror attack in which a baby was killed when it was deliberately run down by a car.

\section{B. Time Spent on a Page}

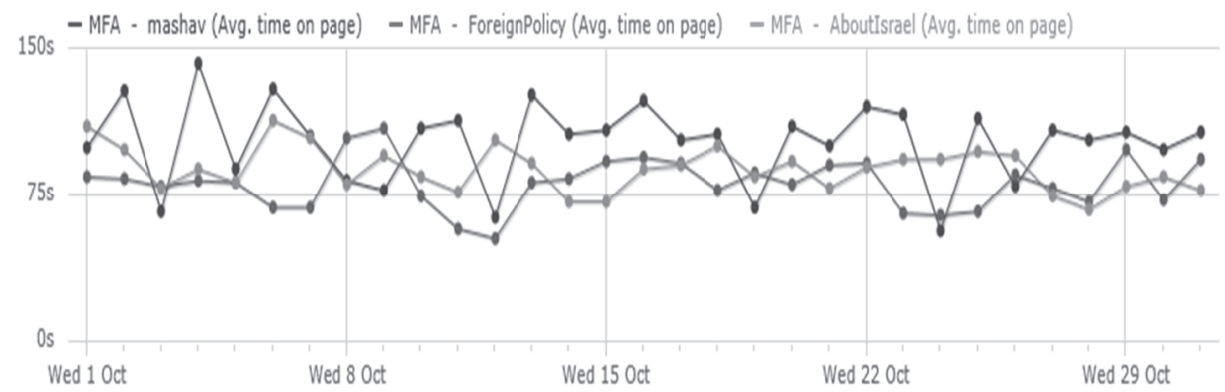

Figure 6 - The graph shows the average time spent by users on the various pages in the three sections: About Israel, Foreign Policy, and MASHAV (October 2014).

1. The average time spent in the sections, in most cases, is more than 75 seconds.

2. The longest average periods of time spent were in MASHAV, with the peak being a little less than 150 seconds. 


\section{Comparison of the February Data and October Data}

In a comparison of the page views data for February and October, there are page views in all three sections that were studied. Most page views were in About Israel, while Foreign Policy was second. MASHAV had the least page views of the three. On the other hand, the average periods of time spent in the MASHAV section were the longest. In February the average periods of time spent in the MASHAV section were one minute and forty-one seconds, and in October they were one minute and forty-four seconds. The MASHAV section also has the longest average periods of time spent on a page, with a peak of slightly less than one hundred and sixty seconds in February and slightly less than one hundred and fifty seconds in October. Apparently, it is the operational nature of the section that causes the lengthy periods of time of page views.

\section{Summary of 2014}

A. Number of Page Views in the Sections

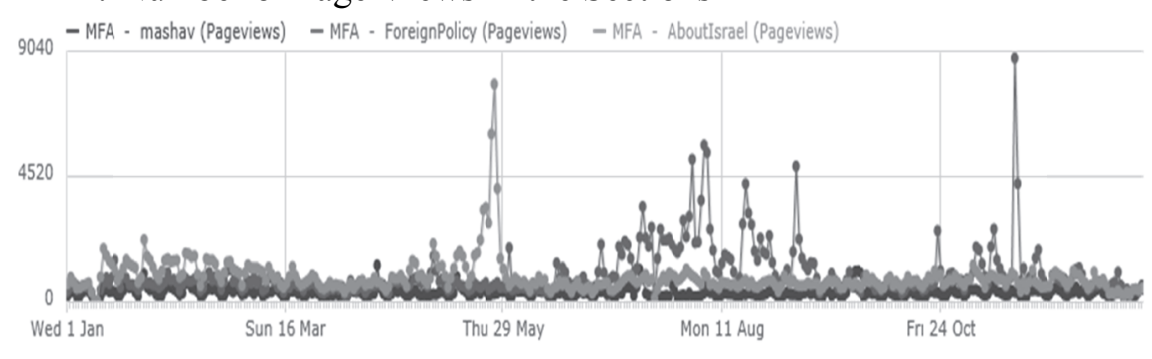

Figure 7 - The graph shows the number of views in the various pages in the three sections: MASHAV, About Israel, and Foreign Policy (Summary of 2014).

1. It is evident that throughout the first half of the year there were more page views in "About Israel" while in the second half there were more page views in "Foreign Policy."

2. We can see that there are some peak points of page views both in "Foreign Policy" and in "About Israel", with MASHAV having low page views data throughout the year.

B. Time Spent on a Page

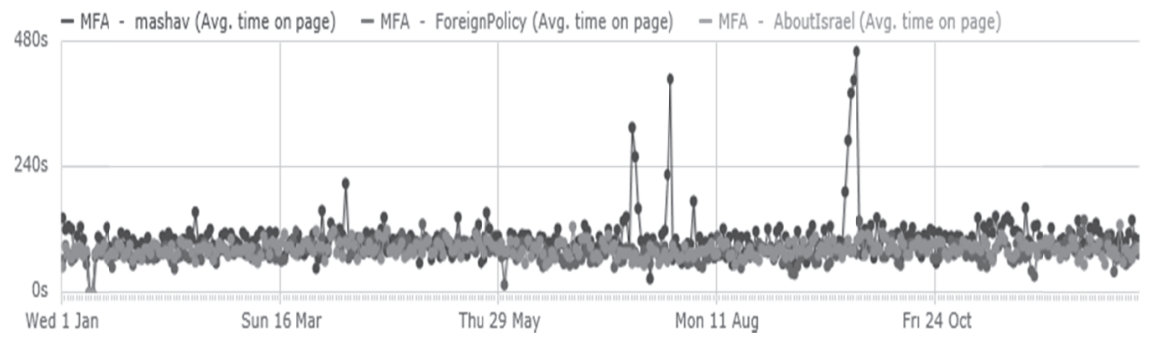

Figure 8 - Time Spent on a Page (Summary of 2014) 
The graph shows the average periods of time spent by users throughout 2014 on the various pages of the three sections - About Israel, Foreign Policy and MASHAV.

The average periods of time spent on a page in 2014 were one minute and fortyfive seconds in MASHAV, one minute and thirteen seconds in Foreign Policy, and one minute and twenty seconds in About Israel. The periods of time spent in MASHAV were lengthier during three periods of the year than the others. MASHAV is also characterized by four leaps in the data.

\section{Conclusions/Trends}

1. This type of system makes it possible to observe divisions and subdivisions throughout various periods of time. These data can serve as criteria that influence the appraisal and the determination of retention periods.

2. It can be seen that for the years and months studied the sections most viewed are About Israel and Foreign Policy. The section with the fewest page views is MASHAV. However, in MASHAV users spent the most time on pages, in accordance with the nature of the site and its operational nature.

3. According to the experience of the director of the website, the minimal significant amount of time spent on a page is at least 60 seconds. This datum requires additional study.

4. An additional element influencing the data presented here, which was not taken into account because it is presently beyond the scope of the research conducted, is the quality of the website from the aspect of its accessibility and links.

5. A study of the entry points of the users and their geographical origins may constitute parameters of significance in the evaluation.

This is the first attempt to examine the user behavior parameter to appraise internet websites. In order to know whether this parameter is valid beyond this specific case study, it is necessary to carry out additional studies which will either confirm the results or indicate the need of other types of examination.

\section{References}

Archives Law 5715-1955. Regulations and Instructions (Hebrew). http://www.archives.gov.il/ ArchiveGov/meyda/TkufotBiur/taknot.htm

Brown A. (2006), Archiving websites: a practical guide for information management professionals. Facet Publishing. pp. 24-41

Prime Minister Office, State Archivist, Higher Archives Council Protocols and Report, Jerusalem (Hebrew)

Schenkolewski-Kroll, S. and Tractinsky, A, (2015). "Archival Appraisal Processes in the Ministry of Foreign Affairs of Israel" in Ministry of Foreign Affairs website final Report, Submitted to the European team of InterPARES Trust (Unpublished)

Shoham, S and Schenkolewski-Kroll, S (2010) Israel: Libraries, Archives and Museums, Encyclopedia of Library and Information Sciences, Third Edition, 1: 1, 3035-3040 
TNA (2011), Web Archiving Guidance (2011). http://nationalarchives.gov.uk/documents/ information-management/web-archiving-guidance.pdf

TNA (2014), Operational Selection Policy OPS 27, UK Central Government Web Estate, http://www.nationalarchives.gov.uk/documents/information-management/osp27.pdf

Zini, A. (2011). The Place of the Filing Unites in the Computerization Era, 2011(Hebrew). http://www.archives.gov.il/ArchiveGov/meyda/ElectronicRashuma/YomIyun2010.htm 